Journal of Advanced Research in Fluid Mechanics and Thermal Sciences

Journal homepage: www.akademiabaru.com/arfmts.html ISSN: 2289-7879

\title{
Parametric Experimental Study of Pressure Drop of Two- Phase Oil (D130)-Water Flow in 4" Diameter Pipe
}

\author{
Syed M. Shaahid ${ }^{1,}{ }^{*}$, Mehaboob Basha $^{1}$, Luai M. Alhems ${ }^{1}$ \\ 1 Centre for Engineering Research - Research Institute, King Fahd University of Petroleum and Minerals, Dhahran, Saudi Arabia
}

\begin{tabular}{|c|c|}
\hline ARTICLE INFO & ABSTRACT \\
\hline $\begin{array}{l}\text { Article history: } \\
\text { Received } 17 \text { February } 2020 \\
\text { Received in revised form } 10 \text { May } 2020 \\
\text { Accepted } 15 \text { May } 2020 \\
\text { Available online } 5 \text { July } 2020\end{array}$ & $\begin{array}{l}\text { The flow of two immiscible liquids oil and water in pipes has been a challenging } \\
\text { research topic since several decades. Oil and water are often produced and } \\
\text { transported together in pipelines over long distances. In oil and chemical industries, } \\
\text { knowledge of the frictional pressure loss (FPD) of oil-water flows in pipes is necessary } \\
\text { to specify the size of the pump required to pump the emulsions. The present } \\
\text { parametric study reports pressure drops measurements of oil (D130)-water flow in a } \\
4^{\prime \prime} \text { diameter stainless steel pipe at different flow conditions. Experiments were carried } \\
\text { out for different water cuts (WC: } 0-100 \% \text { ) and for different inclination angles (including } \\
0^{\circ}, 15^{\circ} \text {, and } 30^{\circ} \text { ). Oil-water flow rates were varied from } 4000 \text { to } 8000 \text { barrels-per-day } \\
\text { in steps of } 2000 \text {. For a given flow rate, the FPD has been found to increase (for all } \\
\text { angles) from WC } 0 \text { - } 60 \% \text {, and thereafter FPD decreases, this could be due phase } \\
\text { inversion. For a given WC }=40 \% \text {, the FPD has been found to increase with angle and } \\
\text { flow rate. It has been noticed that inclination angle has appreciable effect on FPD. Also, } \\
\text { it has been found that the FPD decreases for WC }=0-40 \% \text { for } 0^{\circ} \text { case. With further } \\
\text { increase in WC, FPD increases, this may be due to phase inversion }\end{array}$ \\
\hline
\end{tabular}

Keywords:

Oil(D130)-water flow; Pressure drop;

Water-cut; Angle effect; 4 inch pipe

Copyright @ 2020 PENERBIT AKADEMIA BARU - All rights reserved

\section{Introduction}

The multiphase flow is a complex phenomenon involving simultaneous flow of two or more physically immiscible fluids (such as: oil and water) in pipelines. Also, the widespread occurrence of multiphase flows in pipes is the driving force for extensive research in this area (a number of upstream practical applications in the petroleum industry involve oil-water two-phase flow phenomena).

The physical understanding of two-phase flow characteristics in pipes is of importance since appreciable savings in the pumping power required for oil transportation (water-lubricated transportation of crude oil) can be attained when water flows in the pipeline together with the oil,

\footnotetext{
* Corresponding author.

E-mail address: mshaahid@kfupm.edu.sa
}

https://doi.org/10.37934/arfmts.73.1.146155 
especially when the highly viscous phase is surrounded by a water annulus, giving place to the core annular flow configuration. More importantly, fluids with different properties exhibit different flow regimes in different pipe configurations under different operating conditions. Considerable literature exists on the two-phase flow of oil and water.

$\mathrm{Xu}$ [1] presented a brief review of oil-water two phase flows in horizontal pipes and highlighted future research trends of oil water pipe flows. Yusuf et al., [2] have presented experimental data of flow patterns, pressure gradient and phase inversion in horizontal oil-water flow in a $25.4 \mathrm{~mm}$ acrylic pipe. One of the main findings is the large difference between the pressure gradient results which is attributed to the difference in oil viscosity. The differences between the results become bigger at higher oil velocities. The largest difference in pressure values was observed in flow region where oil is the continuous phase. On the contrary, for dispersed oil in water, the pressure gradient values observed at the same conditions are approximately the same. At low oil velocities, the water velocity required to initiate the transition to non-stratified flow increased as the oil viscosity increased while it decreased at higher oil velocities.

Sotgia et al., [3] performed experimental study of oil-water flow in horizontal pipes using mineral oil and tap water of viscosity ratio about 900 and density ratio 0.9. A set of seven different pipes of Pyrex and Plexiglas where used, with diameters ranging between 21 and $40 \mathrm{~mm}$. Pressure drop measurements, flow pattern maps and pictures of the oil-water flow are reported in this article. AlWahaibi [4] developed a simple power law pressure gradient correlation for horizontal oil-water separated flow (stratified and dual continuous flows). The new proposed correlation predicts the pressure gradient with higher accuracy. Pressure gradient database was prepared for oil-water flow which includes wide range of operational conditions, fluid properties, pipe diameters and materials.

The formation of water-in-crude oil emulsions during oil production can cause a substantial reduction of the production rates. This occurs due to the high effective viscosity of the emulsion that increases with water content towards the phase inversion point. Knowledge of both the effective viscosity and the phase inversion point is important for the dimensioning of pipelines and equipment as well as for the assessment of production strategies. The effective viscosity of an emulsion can greatly exceeds either the crude or the water single phase viscosities. Plasencia et al., [5] made a comparative study of the pipe flow of water-in-crude oil emulsions in a closed loop system (pipe ID2.2cm). The pipe flow of emulsions based on six different crude oils (viscosities from 4.8 to 23.5 $\mathrm{mPas})$ and salt water $(3.5 \% \mathrm{NaCl} \mathrm{w} / \mathrm{v}, \mathrm{pH} 1 / 47.3)$ were investigated experimentally using a small scale flow loop. The effective viscosity of the emulsions as a function of the water fraction was calculated from pressure drop measurements. The point of inversion was observed to be fluid dependent. Poesio et al., [6] have studied experimentally the effect of air injection on liquid-liquid core annular flow of very-viscous-oil/water on the pressure drop. They have presented a new data set for pressure drop.

The modelling of the pressure gradient of oil-water flow in pipelines is very crucial. Accurate prediction of pressure gradient will lead to better design of energy efficient transportation systems. Al-Wahaibi and Mjalli [7] developed an artificial neural network (ANN) model with five inputs (oil and water superficial velocities, pipe diameter, pipe roughness, and oil viscosity) to predict the pressure gradient of horizontal oil-water flow based on a databank of around 765 measurements collected from the open literature. Statistical analysis showed that the ANN model has an average error of $0.30 \%$. Hasanvand and Berneti [8] have also used artificial neural networks (based on 600 data set of Persian Gulf oil) in their study to obtain the oil flow rate as output measurement, The input variables included temperatures and line pressures. Tan et al., [9] conducted experiments (in a $50 \mathrm{~mm}$ diameter horizontal pipe) to measure the individual phase rates of oil-water two phase flow using a Conductance Ring Coupled Cone (CRCC) meter. The accuracy of this method in measuring oil flow 
rate is $2.3 \%$ and for water flow rate is $4.8 \%$. The proposed method improves the accuracy of the measurement by measuring the water holdup in the annular channel.

In experimental investigation to study the slip (holdup) phenomenon between phases in wateroil two phase flows in horizontal pipes was conducted out by Xu et al., [10]. Emphasis was placed on the effects of input fluids flow rates, pipe diameter $(0.05 \mathrm{~m}$ and $0.025 \mathrm{~m})$ and viscosities of oil phase on the slip. Results showed that at low input flow rate, there is a large deviation on the holdup between two flow systems with different oil viscosities and the deviation becomes gradually smaller with increased input water flow rate.

Xu et al., [11] investigated phase inversion and frictional pressure gradients during simultaneous vertical flow of oil and water two-phase through upward and downward pipes. They concluded that the frictional pressure gradient reaches to its lower value at the phase inversion point. Hanafizadeh et al., [12] investigated flow patterns of two-phase oil-water flow in an inclined pipe. They inferred that non-stratified flows such as bubbly and slug flows are dominant flow patterns in the upward flows and stratified flows are dominant flow patterns in the downward flows. Descamps et al., [13] performed investigation of three phase flow in vertical pipes. Attention was paid to phase inversion phenomenon. They noticed that the dispersed water phase has significant impact on the bubble size. Grassi et al., [14] conducted experiments of two-phase liquid-liquid (high viscosity ratio) flows in horizontal and slightly inclined pipes. The results were validated against theoretical models. Du et al., [15] conducted experimental investigation of vertical upward oil-water two phase flows in a $20 \mathrm{~mm}$ diameter pipe. They presented flow pattern map of oil water for different superficial velocities. Strazza et al., [16] conducted experimental study on oil/water flow in horizontal and slightly inclined small pipe plexi- glass tubes (with $21 \mathrm{~mm}$ ID, 9m long). They focused on core-annular flow pattern boundary, pressure drops, and oil hold-up measurements.

loannou et al., [17] investigated phase inversion and its effect on pressure gradient of immiscible (water and oil) liquids for two pipe materials and two pipe sizes for a range of mixture velocities. Phase inversion was observed in all cases preceded by a large increase in pressure gradient. Zhao et al., [18] studied local flow characteristics of oil-water dispersed flow in a vertical upward pipe. The water flow rates varied from $0.12 \mathrm{~m} / \mathrm{s}$ to $0.89 \mathrm{~m} / \mathrm{s}$, while the oil flow rates ranged from $0.024 \mathrm{~m} / \mathrm{s}$ to $0.198 \mathrm{~m} / \mathrm{s}$. The typical radial profiles of interfacial area concentration, oil phase fraction, interfacial velocity, and oil pressure drops were presented. Lum et al., [19] investigated the effect of upward and downward pipe inclinations on the flow patterns, hold up and pressure gradient during twoliquid (water and oil) phase flows for mixture velocities between 0.7 and $2.5 \mathrm{~m} / \mathrm{s}$ and phase fractions between $10 \%$ and $90 \%$. The oil to water velocity ratio was higher for the upward than for the downward flows but in the majority of cases and for all inclinations oil was flowing faster than water. Other studies related to multiphase flow are presented in ref. [20-22].

In the wake of the above literature review, currently no studies are available on frictional pressure drop (FPD) measurements of oil (D130)-water two-phase flow in 4 inch diameter stainless steel pipe at different flow conditions (at different inclinations). This is the motivation for the present experimental study and it places emphasis on the effect of flow rates, water cuts, and inclination angles on pressure drop measurements of oil (D130)-water two-phase flow. In this work, attention has been focused on FPD measurements of oil (D130)-water two-phase flow in 4 inch diameter stainless steel pipe at different flow conditions (at different inclinations). Experiments were carried out for different inclination angles including; $0^{\circ}, 15^{\circ}, 30^{\circ}$ (for water cuts $0 \%, 20 \%, 40 \% 60 \% 100 \%$ ). The oil-water flow rates were varied from 4000 to 8000 BPD in steps of 2000 . The above information is helpful in effectively handling the frictional pressure loss issues. 


\section{Experimental Setup}

The Oil-water two phase experiments were conducted in the flow loop of the multiphase flow laboratory of King Fahd University of Petroleum and Mineral, Dhahran, Saudi Arabia. Details of the loop components and instruments are given in Table 1. Properties of mineral oils Exxsol D130 are listed in Table 2.

The schematic diagram of the flow loop is shown in Figure 1. Experimental set-up includes: four centrifugal variable speed pumps [2 pumps for water (WP) and 2 pumps for oil, (OP)], 4 inch stainless loop, a horizontal separator tank (WOST), which acts as storage tank, two level indicators for oil and water each. The loop is constructed on swinging platform (inclination can be varied from $0^{\circ}-30^{\circ}$ ). The flexible connection (FC) helps in positioning loop at any given angle. The loop is instrumented with a turbine type oil flow meter (OFM), a turbine type water flow meters (WFM), line pressure transmitter (LPT), two flow differential pressure transmitters (DP1 and DP2).

Table 1

Details of equipment of the flow loop

\begin{tabular}{|c|c|c|c|c|}
\hline Items & Manufacturer & Model & Capacity/Range & Accuracy/Error \\
\hline $\begin{array}{l}\text { Four pumps (two } \\
\text { water, two oil) }\end{array}$ & $\begin{array}{l}\text { NEWAR FLOW } \\
\text { SERVE }\end{array}$ & $50-32 C P X 200$ & $35 \mathrm{m3} / \mathrm{hr}$ & - \\
\hline $\begin{array}{l}\text { Two turbine flow } \\
\text { meters }\end{array}$ & Omega & EF10 & $\pm 10 \mathrm{~m} / \mathrm{s}$ & $\pm 1.0 \%$ \\
\hline $\begin{array}{l}\text { Line pressure } \\
\text { gauge }\end{array}$ & ROSEMOUNT & AOB-20 & 0-7 bar & $\pm 0.25 \%$ \\
\hline DP1 & ROSEMOUNT & 300S2EAE5M9 & $\begin{array}{l}0-70 \text { inches of } \\
\text { water column }\end{array}$ & $\pm 0.1 \%$ \\
\hline DP2 & ROSEMOUNT & 300S2EAE5M9 & $\begin{array}{l}0-12 \text { inches of } \\
\text { water column }\end{array}$ & $\pm 0.1 \%$ \\
\hline
\end{tabular}

Table 2

Physical properties of the Exxsol D130 mineral oil

\begin{tabular}{|c|c|c|c|}
\hline Properties & EXXSOL D130 & Units & Test Based On \\
\hline Initial Boiling & 279 & ${ }^{\circ} \mathrm{C}$ & $\mathrm{N} / \mathrm{A}$ \\
\hline \multicolumn{4}{|l|}{ Point (IBP) } \\
\hline Dry Point (DP) & 313 & ${ }^{\circ} \mathrm{C}$ & N/A \\
\hline $\begin{array}{l}\text { Flash Point } \\
\text { (Method A) }\end{array}$ & 140 & ${ }^{\circ} \mathrm{C}$ & ASTM D93 \\
\hline Aromatic & 1.0 & wt\% & ExxonMobil \\
\hline Content & & & Method \\
\hline Density $\left(15.6^{\circ} \mathrm{C}\right)$ & 827 & $\mathrm{~kg} / \mathrm{m}^{3}$ & ASTM D4052 \\
\hline $\begin{array}{l}\text { Vapor Pressure } \\
\left(20.0^{\circ} \mathrm{C}\right)\end{array}$ & $<0.0402$ & Inch $\mathrm{H} 2 \mathrm{O}$ & $\begin{array}{l}\text { ExxonMobil } \\
\text { Method }\end{array}$ \\
\hline $\begin{array}{l}\text { Aniline Point } \\
\text { (Method E) }\end{array}$ & 88 & ${ }^{\circ} \mathrm{C}$ & ASTM D611 \\
\hline $\begin{array}{l}\text { Kinematic } \\
\text { Viscosity }\left(25.0^{\circ} \mathrm{C}\right)\end{array}$ & $6.89 * 10-6$ & $\mathrm{~m}^{2} / \mathrm{s}$ & ASTM D445 \\
\hline
\end{tabular}




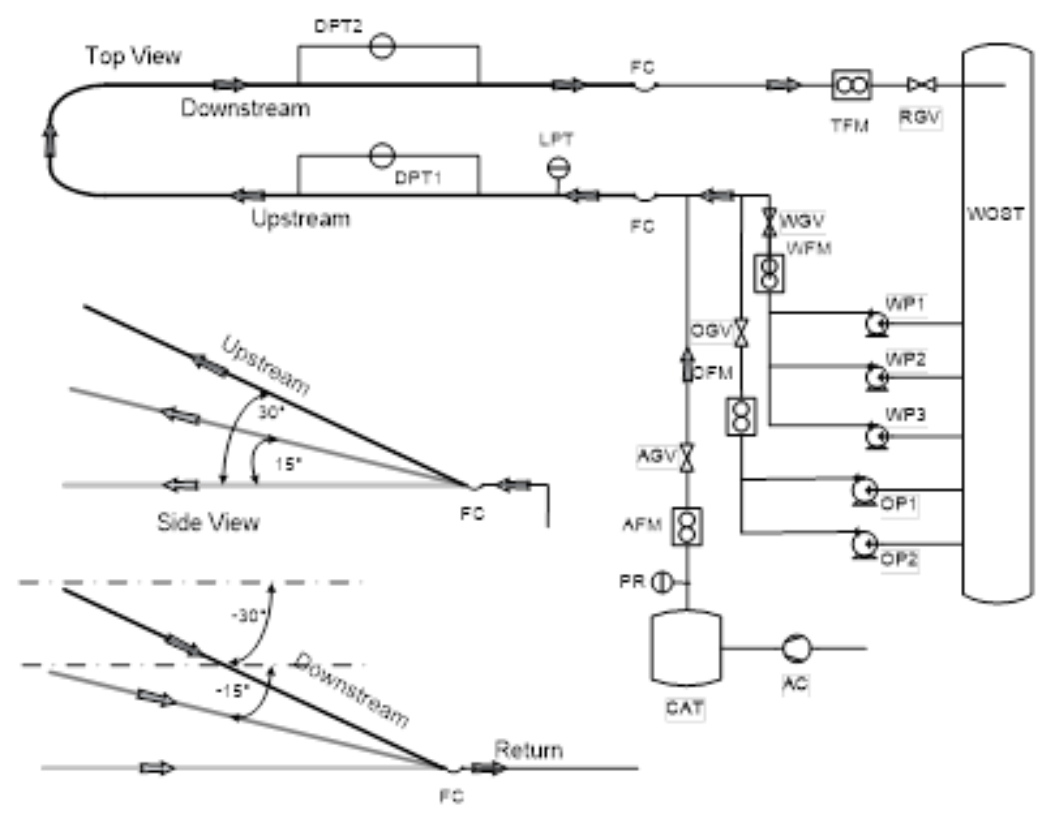

Fig. 1. Schematic layout of the oil-water multiphase flow loop

\section{Experimental Procedure}

In-order to validate the pressure drop measurements against available empirical models, experiments were performed for water-only and oil-only single phase (in 4 inch pipe).

To achieve the above, water was pumped in the loop using centrifugal pumps. Required volume flow rate was attained by varying speed of pumps through variable speed drives and also by regulating oil globe valve (OGV) and water globe valve (WGV) of oil and water flow streams respectively. Turbine flow meters installed on the discharge line of the pumps were used for measuring the flow rates. Return gate valve (RGV, Figure 1) of the loop is throttled to set the required outlet pressure (e.g. 1 bar or 2 bars).

For a given flow rate, experiments were conducted and pressure drop measurements were made at different locations of the loop as shown Figure 1. Once the steady state flow condition is achieved, differential pressure drops are recorded across 3m (DPT1). CR 1000 data logger was used to record experimental data. Similar procedure was followed for oil-only flow experiments.

Pressure drop data was used to calculate friction factor using Eq. (1) and compared with Eq. (2) and Eq. (3).

$$
\mathrm{f}=\frac{\Delta \mathrm{P}}{\mathrm{L}} \frac{2 \mathrm{D}}{\rho \mathrm{v}^{2}}
$$

$\Delta \mathrm{P} \quad$ Pressure drop $(\mathrm{Pa})$

$\mathrm{L} \quad$ Distance between the two pressure taps $(\mathrm{m})$

D Hydraulic diameter of the pipe $(\mathrm{m})$

$\rho \quad$ Fluid density $\left(\mathrm{Kg} / \mathrm{m}^{3}\right)$

$\mathrm{V} \quad$ Average velocity of the fluid $(\mathrm{m} / \mathrm{s})$

$\varepsilon \quad$ Pipe roughness (m)

Re Reynolds number

$f=0.3164 R e^{-1 / 4}$ 
$\frac{1}{\sqrt{\mathrm{f}}}=-2 \log \left[\frac{\varepsilon / \mathrm{D}}{3.7}-\frac{5.02}{\operatorname{Re}} \log \left[\left(\frac{\varepsilon / \mathrm{D}}{3.7}\right)+\frac{13}{\mathrm{Re}}\right]\right]$

The turbulent friction factor can also be determined using other correlations, such as the Zigrang \& Sylvester 1985 correlation defined in Eq. (3) above. Then experimentally obtained friction factor (Eq. (1)) was compared with the friction factors calculated by using Blasius correlation and Zigrang \& Sylvester correlations as shown in the Figure 2. The results showed a close agreement particularly with the Blasius friction factor (Eq. (2)).
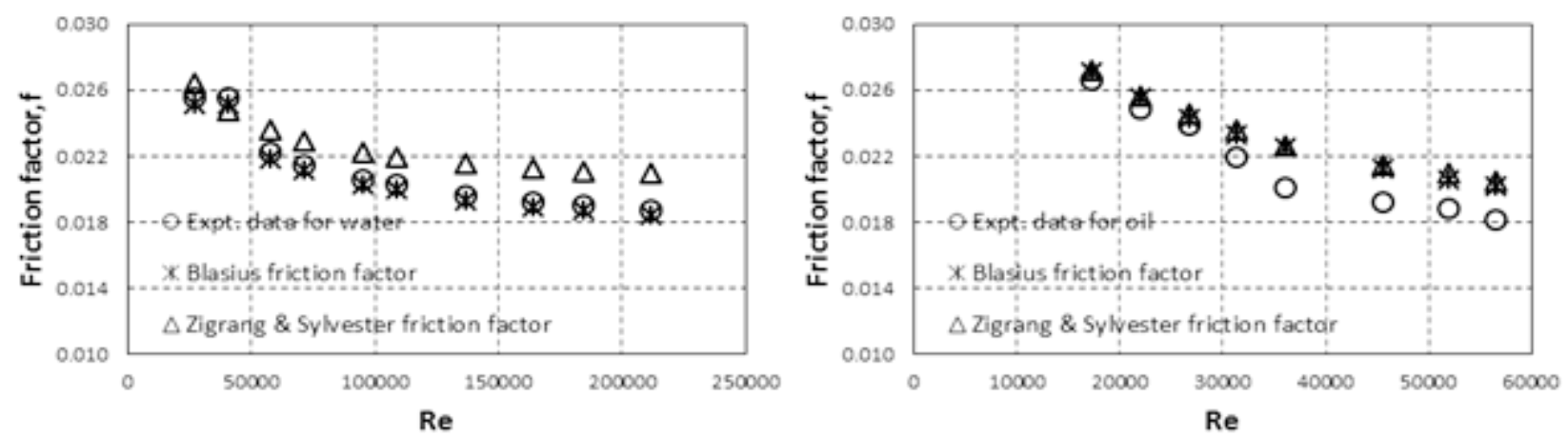

Fig. 2. Friction factor comparisons with Blasius and Zigrang \& Sylvester correlations for oil-water flow

Figure 2 shows the friction factor of single-phase water and oil against Re. It can be noticed that the friction factor decreases with increase in velocity. The experimental data is found to be in good agreement with established theoretical relation. The above experiments were for single phase oil only and water only. However, for a given oil-water multiphase flow, speeds of the oil and water pumps was varied to achieve required flow rate and water cut. Once the required water cut and flow rates are reached, pressure drop [across $3 \mathrm{~m}$ (DPT1)] measurements were made. Similar procedure was followed for other angles including; $15^{\circ}, 30^{\circ}$ and for different water cut ratio 0 to $100 \%$. The oilwater flow rates at the inlet were varied from 4000 to 8000 BPD.

\section{Results and Discussions}

Oil (D130)-water two phase flow experiments were carried out for different inclination angles including; $0^{\circ}, 15^{\circ}, 30^{\circ}$ and for different water cut ratios (0\%, 20\%, 40\%,60\% and $\left.100 \%\right)$. The oil-water flow rates were varied from 4000 to 8000 barrels-per-day (BPD).

\subsection{Effect of Water-Cut on Oil-Water Frictional Pressure Drop (FPD) For Different Flow Rates}

Figure 3(a) shows the effect of water cut for different flow rates on pressure drop. It can be seen from Figure 3(a) that at a given flow rate the pressure drops decreases from WC $=0$ to WC $40 \%$ whereas for WC $40 \%$ to WC $60 \%$, friction pressure drop has been found to increase. This could be due phase inversion. However, for $W C=100 \%$, frictional pressure drop is lower as compared to frictional pressure at $W C=0 \%$. This is due to lower viscosity of water. Also, it can be observed from Figure 3(a), that at any given WC, the frictional pressure drops increases with increase in flow rate. For a given water cut WC $=40$, increasing in BPD from 4000 to 6000, percentage increase in frictional pressure drop is about $150 \%$. Figure $3(\mathrm{~b})$ shows the effect of flow rate on frictional pressure drop for different water cuts. As stated earlier, it can be seen from Figure 3(b), pressure drop increases with flow rate and WC. The frictional pressure has been found to increase linearly with respect flow rate. However, effect of water cut on frictional pressure drop is not linear. For a given flow rate 6000 BPD, 
increasing in water cut from WC 20 to 40, percentage increase in frictional pressure drop is about $17 \%$.

For a given angle $\theta=15^{\circ}$ case, the effect of water cut for different flow rates on pressure drop is shown in Figure 4(a). As it can be seen from Figure 4(a), for a given flow rate the pressure drops increases from WC $=0$ to WC $60 \%$. Further increase in WC, shows decrease in FPD has been found to decrease. This could be due to phase inversion or change in flow pattern regime. Also, it can be seen from Figure 4(a), for any given WC, the FPD increases with increase in flow rate.

For $\theta=30^{\circ}$ case, the effect of flow rate on FPD for different water cuts is shown in Figure $4(\mathrm{~b})$. As it can be seen from Figure 4(b), FPD increases with flow rate and WC. However, FPD is relatively higher for WC $=0$ to WC $60 \%$ as compared $\theta=15^{\circ}$ case. This could be due to increase in inclination angle.
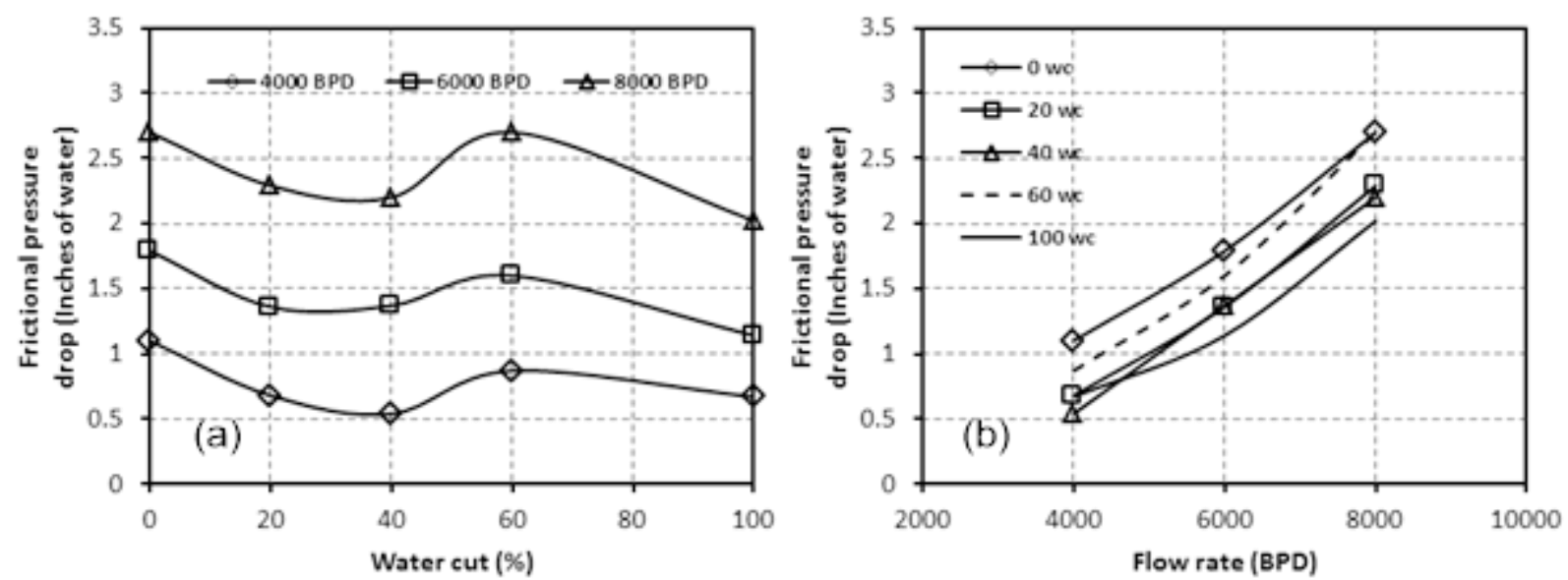

Fig. 3. Frictional pressure drops behavior. (a) Effect of water cut on pressure drop for different flow rates, (b) Effect of flow rate on pressure drop for different water cuts $\left(0^{\circ}\right.$ case)
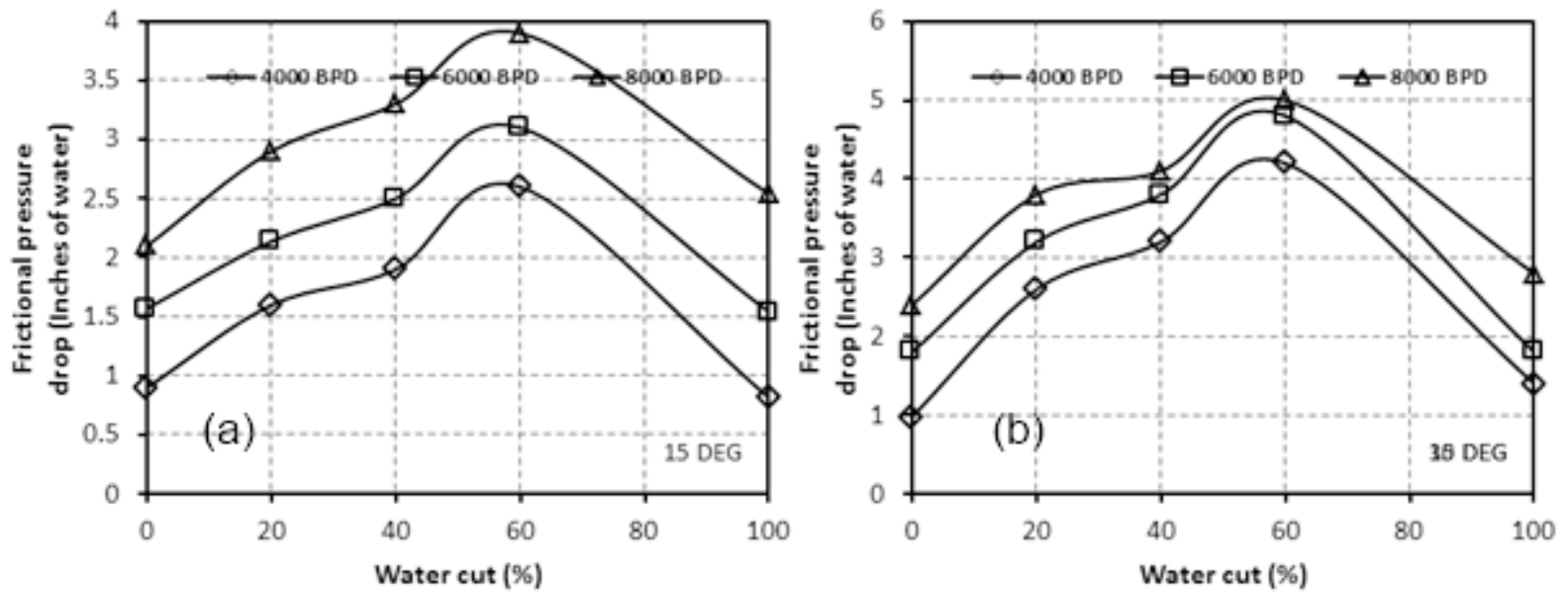

Fig. 4. Effect of water cut on pressure drop for different flow rates. (a) $15^{\circ}$ case, (b) $30^{\circ}$ case

\subsection{Effect of Flow Rate on Oil-Water Pressure Drop for Different Water-Cuts}

For a given angle $\theta=15^{\circ}$, the effect of flow rate on frictional pressure drop (FPD) for different WC is shown in Figure 5(a). As it can be seen from Figure 5(a), pressure drop increases with flow rate and WC. The FPD drop has been found to increase linearly with respect flow rate. For a given flow rate of 6000 BPD, for increase in water cut from WC 0 to 20, percentage increase in FPD is about $36 \%$. For angle $\theta=30^{\circ}$ case, the effect of flow rate on FPD for different water cuts is shown in Figure 5(b). 
Again, as it can be seen from Figure 5(b), FPD increases with flow rate and WC. However, pressure drops are relatively higher as compared $\theta=15^{\circ}$ case. This could be due to increase in inclination angle. For a given flow rate of 6000 BPD, for increase in water cut from WC 0 to 20, percentage increase in frictional pressure drop is about $77 \%$. From these figures, it can be concluded that the effect of inclination on pressure drop behaviour is appreciable.
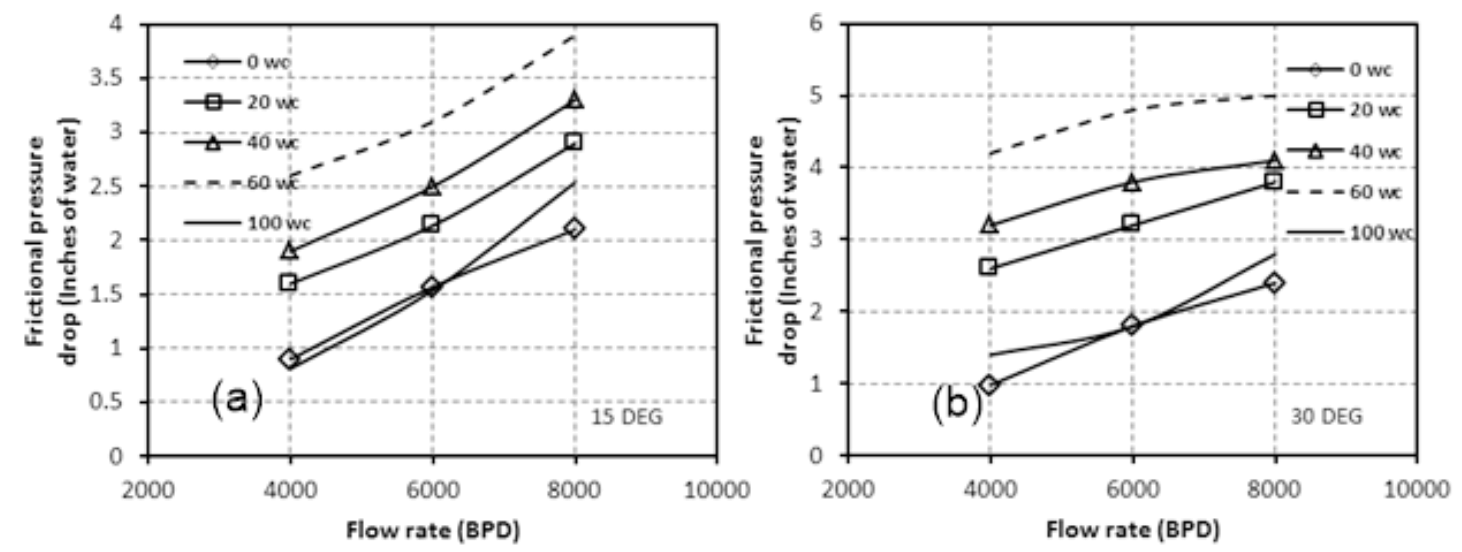

Fig. 5. Effect of flow rate on pressure drop for different water cuts (a) $15^{\circ}$ case, (b) $30^{\circ}$ case

\subsection{Effect of Inclination on Oil-Water Pressure Drop for Different Flow Rates for Given Water Cut}

For the sake of brevity, the angle effect on pressure drop measurements for different flow rates, only water cut $(\mathrm{WC})=40 \%$ has been presented.

For a given water cut (WC $=40 \%)$, the effect of inclination for different flow rates on pressure drop is shown in Figure 6. As mentioned earlier, in general for all angles, pressure drop increases with flow rate and water cut. The effect of angle has found to be appreciable. For a given flow rate 8000 $\mathrm{BPD}, \mathrm{WC}=40 \%$, increase in angle from 0 to $15^{\circ}$, percentage increase in frictional pressure drop is about 50\%. However, for further increase in angle from $15^{\circ}$ to $30^{\circ}$, percentage increase in frictional pressure drop is about $24 \%$.

The total pressure head (TPH) is sum of frictional and gravitational pressure head (GPH). The present work has focused on frictional pressure head (FPH). However, GPH is a constant term which may be added to FPH to obtain the TPH. For a given angle, $\theta=15^{\circ}, \mathrm{GPH}(\rho g \mathrm{~h}=\rho \mathrm{g} \sin \theta \mathrm{h}, \rho$ is mixture density, $\mathrm{h}$ is distance between pressure tapping points, $\mathrm{g}$ is gravity) is 23.13 inches of water.

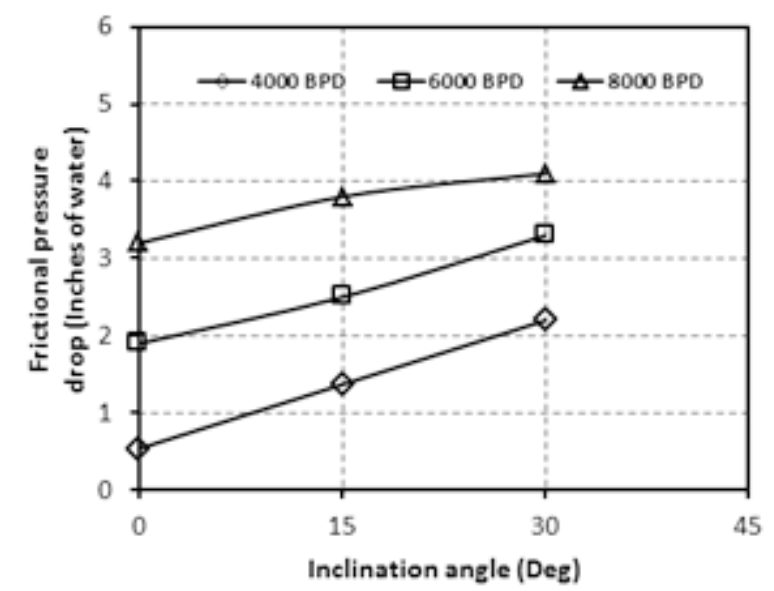

Fig. 6. Effect of angle on pressure drop for different flow rates (for a given water cut, WC = 40\%) 


\section{Conclusions}

The present work has focused attention on the pressure drop measurements of oil (D130)-water two-phase flow in a horizontal and inclined 4 inch diameter stainless steel pipe at different flow conditions. Experiments were performed for different inclination angles including; $0^{\circ}, 15^{\circ}, 30^{\circ}$ and for different water cut ratios (0\%, 20\%, 40\%,60\% and 100\%). The flow rates were varied from 4000 to 8000 BPD. In order to validate the experimental work, the measured pressure drops and friction factor of single-phase oil and single-phase water were compared with existing empirical relations and good agreement was noticed.

For a given flow rate, the frictional pressure drop has been found to decrease for WC $=0$ to WC $40 \%$ for $0^{\circ}$ case. Further increase in WC, friction pressure drop has been found to increase. The frictional pressure has been found to increase linearly with respect flow rate. However, effect of water cut on frictional pressure drop is not linear.

For a given flow rate (for all angles) the frictional pressure drops (FPD) has been found to increase from WC $=0-60 \%$. Further increase in WC causes FPD to decrease. For a given flow rate of 6000 $\operatorname{BPD}\left(\theta=15^{\circ}\right)$, with increase in WC from 0 to 20 , percentage increase in FPD is about $36 \%$. Further increase from $15^{\circ}$ to $30^{\circ}$, percentage increase in FPD has been found to be about $77 \%$.

\section{Acknowledgement}

The authors would like to acknowledge the support of King Fahd University of Petroleum and Minerals for this research work.

\section{References}

[1] Xu, Xiao-Xuan. "Study on oil-water two-phase flow in horizontal pipelines." Journal of Petroleum Science and Engineering 59, no. 1-2 (2007): 43-58.

https://doi.org/10.1016/i.petrol.2007.03.002

[2] Yusuf, N., Y. Al-Wahaibi, T. Al-Wahaibi, A. Al-Ajmi, A. S. Olawale, and I. A. Mohammed. "Effect of oil viscosity on the flow structure and pressure gradient in horizontal oil-water flow." Chemical Engineering Research and Design 90, no. 8 (2012): 1019-1030.

https://doi.org/10.1016/i.cherd.2011.11.013

[3] Sotgia, Giorgio, Paolo Tartarini, and Enrico Stalio. "Experimental analysis of flow regimes and pressure drop reduction in oil-water mixtures." International Journal of Multiphase Flow 34, no. 12 (2008): 1161-1174.

https://doi.org/10.1016/j.ijmultiphaseflow.2008.06.001

[4] Al-Wahaibi, Talal. "Pressure gradient correlation for oil-water separated flow in horizontal pipes." Experimental Thermal and Fluid Science 42 (2012): 196-203. https://doi.org/10.1016/i.expthermflusci.2012.04.021

[5] Plasencia, Jose, Bjørnar Pettersen, and Ole Jørgen Nydal. "Pipe flow of water-in-crude oil emulsions: Effective viscosity, inversion point and droplet size distribution." Journal of Petroleum Science and Engineering 101 (2013): 35-43.

https://doi.org/10.1016/i.petrol.2012.11.009

[6] Poesio, Pietro, Domenico Strazza, and Giorgio Sotgia. "Very-viscous-oil/water/air flow through horizontal pipes: Pressure drop measurement and prediction." Chemical Engineering Science 64, no. 6 (2009): 1136-1142. https://doi.org/10.1016/i.ces.2008.10.061

[7] Al-Wahaibi, Talal, and Farouq S. Mjalli. "Prediction of horizontal oil-water flow pressure gradient using artificial intelligence techniques." Chemical Engineering Communications 201, no. 2 (2014): 209-224. https://doi.org/10.1080/00986445.2013.766603

[8] Hasanvand, M., and S. M. Berneti. "Predicting oil flow rate due to multiphase flow meter by using an artificial neural network." Energy Sources, Part A: Recovery, Utilization, and Environmental Effects 37, no. 8 (2015): 840-845. https://doi.org/10.1080/15567036.2011.590865

[9] Tan, Chao, Wei Dai, Hoi Yeung, and Feng Dong. "A Kalman estimation based oil-water two-phase flow measurement with CRCC." International Journal of Multiphase Flow 72 (2015): 306-317.

https://doi.org/10.1016/i.ijmultiphaseflow.2014.06.014 
[10] Xu, Jing-yu, Ying-xiang Wu, Fei-fei Feng, Ying Chang, and Dong-hui Li. "Experimental investigation on the slip between oil and water in horizontal pipes." Experimental Thermal and Fluid Science 33, no. 1 (2008): 178-183. https://doi.org/10.1016/i.expthermflusci.2008.07.011

[11] Xu, Jing-yu, Dong-hui Li, Jun Guo, and Ying-xiang Wu. "Investigations of phase inversion and frictional pressure gradients in upward and downward oil-water flow in vertical pipes." International Journal of Multiphase Flow 36, no. 11-12 (2010): 930-939. https://doi.org/10.1016/i.ijmultiphaseflow.2010.08.007

[12] Hanafizadeh, Pedram, Alireza Hojati, and Amir Karimi. "Experimental investigation of oil-water two phase flow regime in an inclined pipe." Journal of Petroleum Science and Engineering 136 (2015): 12-22. https://doi.org/10.1016/i.petrol.2015.10.031

[13] Descamps, M. N., R. V. A. Oliemans, G. Ooms, and R. F. Mudde. "Experimental investigation of three-phase flow in a vertical pipe: Local characteristics of the gas phase for gas-lift conditions." International Journal of Multiphase Flow 33, no. 11 (2007): 1205-1221. https://doi.org/10.1016/j.ijmultiphaseflow.2007.06.001

[14] Grassi, B., D. Strazza, and P. Poesio. "Experimental validation of theoretical models in two-phase high-viscosity ratio liquid-liquid flows in horizontal and slightly inclined pipes." International Journal of Multiphase Flow 34, no. 10 (2008): 950-965. https://doi.org/10.1016/i.ijmultiphaseflow.2008.03.006

[15] Du, Meng, Ning-De Jin, Zhong-Ke Gao, Zhen-Ya Wang, and Lu-Sheng Zhai. "Flow pattern and water holdup measurements of vertical upward oil-water two-phase flow in small diameter pipes." International Journal of Multiphase Flow 41 (2012): 91-105.

https://doi.org/10.1016/i.ijmultiphaseflow.2012.01.007

[16] Strazza, Domenico, Benedetta Grassi, Marco Demori, Vittorio Ferrari, and Pietro Poesio. "Core-annular flow in horizontal and slightly inclined pipes: Existence, pressure drops, and hold-up." Chemical Engineering Science 66, no. 12 (2011): 2853-2863. https://doi.org/10.1016/i.ces.2011.03.053

[17] Ioannou, Karolina, Ole Jorgen Nydal, and Panagiota Angeli. "Phase inversion in dispersed liquid-liquid flows." Experimental Thermal and Fluid Science 29, no. 3 (2005): 331-339. https://doi.org/10.1016/j.expthermflusci.2004.05.003

[18] Zhao, Dongjian, Liejin Guo, Xiaowei Hu, Ximin Zhang, and Xin Wang. "Experimental study on local characteristics of oil-water dispersed flow in a vertical pipe." International Journal of Multiphase Flow 32, no. 10-11 (2006): 12541268. https://doi.org/10.1016/i.ijmultiphaseflow.2006.06.004

[19] Lum, JY-L., T. Al-Wahaibi, and P. Angeli. "Upward and downward inclination oil-water flows." International Journal of Multiphase Flow 32, no. 4 (2006): 413-435. https://doi.org/10.1016/i.ijmultiphaseflow.2006.01.001

[20] Sakr, Ismail M., Wageeh Ahmed El-Askary, Ashraf Balabel, and K. Ibrahim. "Computations of upward water/air fluid flow in vertical pipes." CFD Letters 4, no. 4 (2012): 193-213.

[21] Sukamta, Sukamta. "Computational Fluid Dynamics (CFD) and Experimental study of Two-Phase Flow Patterns GasLiquid with Low Viscosity in a Horizontal Capillary Pipe." CFD Letters 11, no. 8 (2019): 16-23.

[22] Siddegowda, Parashurama, Govindegowda Mundur Sannappagowda, Srinath Mandya Sridharamuthy, and Ramesha Devarahalli Kempegowda. "CFD Analysis of Dual-Phase Flows Inside Helically Coiled Tubes in Vapour Compression Micro-Refrigerator." CFD Letters 11, no. 2 (2019): 81-94. 